\title{
Selection of ecologically efficient and energetically economic engineering-ecological system for municipal solid wastes collection
}

\author{
Oksana Paramonova ${ }^{1},{ }^{*}$ Vadim Bespalov ${ }^{1}$, and Ekaterina Lysova ${ }^{1}$ \\ ${ }^{1}$ Don State Technical University, pl. Gagarina, 1, Rostov-on-Don, 344010, Russia
}

\begin{abstract}
The problem of handling of solid municipal wastes (SMW) is becoming more and more difficult every year, which is caused by the growth of waste mass, changes in their structures and characteristics, absence of economic conditions for processing of the majority of wastes in many countries, financial losses due to burial of precious components of wastes and other reasons. In major cities the most intensive creation and accumulation of SMW is happening in the sources of their creation (residential and public buildings of various public services and amenities and purpose, enterprises, cities, yard territories), which in case of unduly disposal and deactivation could substantially pollute the environment (E). With the purpose of improvement of the activity on handling of SMW and improvement of ecological state of urban territories public utility services enterprises are functioning. Their activity lies in the provision of collection, transportation and utilization of all wastes created in the city. One of the major stages of SMW handling, where both E pollution sources and enterprises on their disposal are involved, is the collection of wastes. That is why in this article the solution of the pressing problem on increase of ecological safety of urban territories based on the selection of ecologically efficient and energetically economic engineering-ecological system for SMW is represented.
\end{abstract}

\section{Introduction}

Creation of whirlwind growing amount of wastes [1-4] is a problem of the majority of countries of the world, since it is connected with the necessity to provide for ecological safety of urban territories, creation of favourable conditions for well-being of the population, sanitary cleaning of urban territories, environmental protection and preservation of resources [3, 5-8]. That is why in the complex of ecological problems a special place is taken by the necessity to create a system of wastes management based on simulation of ecologically efficient and energetically economic SMW handling on the stages of collection, transportation and utilization of wastes, providing for ecological safety of urban territories.

\footnotetext{
"Corresponding author: paramonova_oh@mail.ru
} 
Works of V.I. Bespalova [9-11], E.E. Borovskoy [12], Ya.I. Viersman [13], V.M.Garin [14], V.A. Grachev [15], A.S. Grinin [5], A.N.Mirniy, V.N. Novikov [3], V.I. Smetanin [16], L.Ya Shubov [6, 17]. and others are dedicated to examination of the problem of wastes handling. Development of various programs, concepts and systems of wastes handling with consideration to influence of natural and climatic, physical and geographic peculiarities and resource and economic importance of urban territories has also been done by O.M.Cherp, V.N. Vinichenko [18], Robin Murray [19], Ruta Bendere [20], Forbes R. McDougall, Peter R. White [21] and others.

Provision of ecological safety of urban territories is inseparable connected with development of the system of SMW handling, main stages of which are collection, transportation and utilization of wastes implemented with the help of various methods, ways and technical means $[6,10,13,15,22-24]$, the selection of which at present is realized, as a rule, on basis of economic comparison of alternative ways and simplicity of technical implementation. At that as the criteria for choosing of such ways mainly only the indicated economic expenses on their implementation are used.

Under the conditions of rational use of natural and energy resources taking into consideration their high value a special meaning is given to the conjugate solution of the issues of provision of ecological safety and energy preservation based on scientifically ground methodological approach to selection at the stage of designing and improvement of the system of SMW handling with the purpose of increase of its ecological efficiency and energetical economy by implementation of engineering-ecological events either from the number of known ones, or by development of absolutely new events, providing, first of all, collection of wastes which, in the end, determines the timeliness of the issue of research.

\section{Theory or experimental methods}

In the works $[2-4,11,25-27]$ results of examination of characteristics of SMW are represented based on examination of SMW themselves from the position of the theory of stability of disperse systems, which allowed to group parameters of characteristics of SMW, explained patterns of SMW interaction with main components of $\mathrm{E}$ and build physical models of processes of pollution [28] and decrease of pollution of $E$ with solid wastes [29, 30].

On basis of creation of a physical model of the process of E pollution [28], reflecting the interconnection of each stage of handling of SMW, taking into consideration that as a stage part of the process could be perceived characterizing a complex of stages determining quality difference of activity in implementation of the process, we have organized the stages of the E pollution process with SMW in implementation of their "life cycle" with consideration to peculiarities of the reviewed urban territory, characteristics of pollution sources with wastes of the $\mathrm{E}$ in general and its certain components [31-33].

Physical model of the pollution process [28] is taken as a basis for physical simulation of the process of decrease of E pollution [29], the essence of which, in our opinion, is in presenting the implemented separate parts of the process as an aggregate of consecutive and purposeful similar stages of the SMW handling system, corresponding, in their turn, to each stage of the process of E pollution with SMW.

A main condition of the ecological safety of implementation of the process of decrease of E pollution with wastes in the urban territories is provision of high values of ecological efficiency (on the basis of achievements of regulatory requirements) and energy efficiency. At that the most important stage from the ecological point of view is collection of SMW for which the indicated above parameters are the most significant.

Based on the research we have held [27-30, 34], implementation of SMW collection, as one of the main stages, allows to decrease their negative influence on $\mathrm{E}$ in the places of 
their creation, accumulation and distribution of wastes on the territory limited in space (by the dimensions of the premise or territory adjoining the facility). At that the main purpose of this stage is caution of exit of SMW losses from the general volume.

In practice, as a rule, collection of SMW is organized in urban territories, as:

- container less collection («axis» system), i.e. collection of wastes by the vehicles coming on certain days/hours on roadside verge or ramp, characterized by the advantage of absence of additional expenses on equipping of places for SMW collection. However, among disadvantages the following could be distinguished: bags/containers placed on the road are seen from the distance, which creates aesthetic disharmony; they are the object of attention for animals, which could lead to mechanic damage to bags and spilling of wastes; availability of additional staff is necessary for loading of bags/containers; mechanical damage to bags during loading is possible; schedule of transportation is not adhered to; during winter time and heavy precipitation and violations of schedule covering of wastes with snow is possible; rather long route of transportation, due to which transportation expenses are higher [13];

- collection into the non-changeable containers of various modifications, sizes and constructions implies placing of one or several containers on specially equipped ground (concrete or asphalt covered). Container ground is located within the reach of dump truck and is serviced by centralized planned regular scheme;

- collection into changeable containers (bunkers) used, as a rule, for collection of SMW in multi-storied buildings zones and from infrastructure facilities.

Based on the known methods, selection of this or that container, their number, ways of placing (singular, group, separate, joined at container grounds, etc.) depend on many factors - distance to the facility of SMW creation to the transhipment station or utilization facility, type of residential area, size of urban area, population density, etc. [13, 35-37]. Variant of container selection is also determined by the amount of created SMW, state of roads (possible load by tonnage), removal arm (the bigger it is, the more advantageous it is to use big containers) and available vehicles for SMW removal. At that ecological efficiency and energy economy as influencing on the selection of types of containers, as a rule, are taken into consideration rather indirectly [38-41, 43].

Regardless of the chosen technology of SMW collection it is important to exclude, and if not possible - to limit, unauthorized access to SMW of marginalized segments of population, insects, birds and animals, otherwise arousal of serious sanitaryepidemiological risk is possible.

Thus, to provide for ecological safety of urban [41-47] territories during implementation of the system of SMW handling, in general, and their collection, in particular, in our view, it is necessary to use the abovementioned criteria: ecological efficiency and energetic economy.

\section{Experimental section}

Methods of examination are based on the main statements of the theory of dispersion systems, system analysis, analytical generalization of the known scientific and practical results.

\section{Results and Discussion section}

Since presently there is a significant choice of various technological solutions for collection of SMW which could be used for the same urban conditions, for choosing of optimal variant it is necessary to be guided by determination of two criteria, in accordance with the 
reviewed physical model of the process of decrease of $\mathrm{E}$ pollution [29, 30, 42, 44]: ecological efficiency and energetic economy.

Ecological efficiency of implementation of the process of collection, in our opinion, characterizes the degree of decrease of amount of SMW $\left(\mathrm{M}_{1}-\mathrm{M}_{2}\right)$ in relation to initial amount of created wastes $\left(\mathrm{M}_{1}\right)$ due to consecutive implementation of the process of decrease of E pollution, and energetic economy, in its turn, characterizes the share of energy spent on achievement pf the purpose of the process of pollution decrease (useful energy) $\left(\Sigma \mathrm{W}_{\mathrm{i}}\right)$, relatively to the energy spent on implementation of the process in general $\left(\Sigma \mathrm{N}_{\mathrm{i}}\right)$.

These criteria are mutually reinforcing and characterizing the process of E pollution decrease the most fully.

In accordance with the suggested definitions of the criteria of evaluation of the implementation of the process of SMW collection it is possible to represent their indirect dependencies in the general view by their definition as follows:

$$
\text { ecological efficiency } \mathrm{E}_{\mathrm{ef}}=\frac{M_{1}-M_{2}}{M_{1}} \cdot 100 \%
$$

$$
\text { energetic economy } \quad E=\frac{\sum_{i=1}^{n} W_{i}}{\sum_{i=1}^{n} N_{i}} \cdot 100 \% \quad \%
$$

As practice shows, degree of decrease of E pollution is the higher, the more efficient is the implementation of collection in the places of SMW creation.

Examination of physical essence of the process of SMW collection allowed to obtain parametric dependencies of ecological efficiency of SMW collection for the conditions of urban territory $[2,12,26,27]$

$$
E^{\text {coll }} e_{\text {ef }}=\sum_{j=1}^{n}\left[\left(1-\left(1-\frac{2}{3}\left(\frac{32 B \cdot M_{S M W}}{9 \mu_{d . v .} \cdot V_{v o l} \cdot v_{v o l} \cdot \rho_{S M W} \cdot l_{v o l} \cdot D_{\text {eq.d. part }}{ }^{2}}\right)^{1,5} \cdot\left(1-0,055 \pi \cdot \mu_{d . v .} \cdot D_{\text {eq part }}{ }^{2}\right)\right)\right]\right.
$$

and energetic economy (energy intensity index) of SMW collection [2, 12, 26, 27]

$$
E=\frac{0.033 \cdot 10^{-25} \cdot \sum_{j=1}^{n} M_{S M W} \cdot V_{v o l .} \cdot n_{1} \cdot S+\sum_{j=1}^{n} \frac{F_{a d h}}{\pi \cdot \tau_{a d h}}}{\sum_{j=1}^{n} N_{1}+N_{2}+\ldots+N_{n}}
$$

where $B \approx 10^{-26}$ - is the permanent of intermolecular interaction, $\mathrm{J} \cdot \mathrm{m}^{2} ; M_{S M W}$ - is specific weight of SMW based on values of the accumulation norm per 1 unit of account, $\mathrm{kg} ; \mu_{d . v .}-$ is the dynamic air viscosity, $\mathrm{Pa} \cdot \mathrm{s} ; V_{v o l}-$ is the volume of tank for SMW collection, $\mathrm{m}^{3} ; v_{v o l}$-is the speed of movement of a vehicle, $\mathrm{m} / \mathrm{sec} ; \rho_{S M W}-$ is the SMW density, $\mathrm{kg} / \mathrm{m}^{3} ; l_{v o l}$ - is the linear dimension of a vehicle, $\mathrm{m}$; $D_{\text {eq. d. part }}$ - is the equivalent diameter of SMW particles, $\mathrm{m} ; n_{1}$ - is the number of collected SMW particles into $1 \mathrm{~m}^{3}$ of the tank in the unit of time, $1 /\left(\mathrm{m}^{3} \cdot \mathrm{sec}\right) ; S$ - is the area of the cleaned territory surface, $\mathrm{m}^{2} ; \mathrm{F}_{\text {adh }}$ - is the area of adhesion interaction of particles directed into the unit of volume $\left(\mathrm{m}^{3}\right)$ for collection, $\mathrm{m}^{2} / \mathrm{m}^{3} ; \tau_{\text {adh }}-$ is the time of adhesion interaction, sec. 
Improvement of the system of SMW handling should be based upon the analysis of parametric dependencies of the resulting parameters of collection - ecological efficiency and energy intensity index, allowing to find the ways of management of the process of decrease of E pollution with the purpose of increase of its efficiency and economic feasibility, thus providing for sanitary norms of urban territories. As the changeables should be chosen those functionally independent parameters the changes of which lead to simultaneous increase of values of both efficiency and energy intensity index.

Thus, as the result of the research held, the possibility was reached to provide for ecological safety on certain parts of urban territories at the account of prevention of SMW losses by increase of efficiency and economic feasibility of the collection process, and also improvement of technical means for their implementation.

\section{Conclusion}

The obtained parametric dependencies of ecological efficiency and energy intensity index of implementation of SMW collection are most fully reflecting the peculiarities of interaction of SMW with certain functional elements of the system of decrease of negative impact of SMW on E and could be used as optimization criteria for forecasting and evaluation of the degree of ecological safety and energetic economy of different types of such systems.

Thus, viewing SMW as disperse systems, having examined their characteristics and peculiarities of interaction on each stage of their "life cycle" with E components, we have obtained the possibility on basis of the chosen criteria and changes of parameters of the process of decrease of negative impact of SMW on E to provide for sanitary norms of urban territories.

\section{References}

1. Europeans practice of waste management: problems, solutions and prospects (2005)

2. V.V. Zhurkovich, A. I. Potapov, Municipal waste (2001)

3. A.N. Peace, Communal ecology: Encyclopedic Handbook (2007)

4. URL: http://portaleco.ru/ekologija-goroda/sostav-svojstva-i-obem-tverdyh-bytovyhothodov.html

5. A. S. Grinin, V. N. Novikov, Industrial and domestic waste: storage, disposal, recycling (2002)

6. L. Y. Shubov, A. K. Golubin, V. V. Devyatkin, Concept of solid waste management (2000)

7. O. N. Paramonova, Topical Issues of Chemical Engineering and Environmental Protection, 130-132 (2013)

8. O. N. Paramonova, Modern society, education and science, Part 1, 133-134 (2013)

9. V. I. Bespalov, O.N. Paramonova, News RSSU, number 14, 97-104 (2011)

10. V. I. Bespalov, O.N. Paramonova, Collection of Scientific Papers SWorld. Scientific research and its practical application. Current status and development trends 2012, 3 (9), 89 (2012)

11. V. I. Bespalov, O. N. Paramonova, Naukovedenie, 5 (18) (2013)

12. E. E. Borovsky, Industrial and domestic waste: environmental problems (2007) 
13. Ya. Weisman, V. N. Korotaev, N. N. Slyusarev, Waste Management. Collection, transport, compaction, sorting municipal solid waste (2012)

14. V. M. Garin, N. A. Klenow, A. G. Tail, Technology and utilization of waste (2005)

15. V. A. Grachev, A. T. Nikitin, S. A. Fomin, Handling the production and consumption of ecological safety system wastes (2008)

16. V. I. Smetanin, Environmental protection from waste production and consumption (2003)

17. L. Y. Shubov, M. E. Stavrovsky, A. V. Olejnik, Technology of municipal solid waste (2013)

18. O. M. Cherp, V. N. Vinichenko, Problem of municipal solid waste: an integrated approach (1996)

19. R. Murray, Target - Zero Waste (2004)

20. Ruta Bendere, Waste management (2003)

21. F. R. McDougall, P. R. White, M. Franke, P. Hindle, Integrated Solid Waste Management: A Life Cycle Inventory, (2008)

22. O. N. Paramonova, E. P. Lisova, Current issues in scientific work and educational activities, 8, 107-108 (2013)

23. I. Babanine, Recycle Revolution, How to solve the waste problem at minimal cost (2008)

24. L. N. Beldeeva, S. Lazutkina, L. F. Komarova, Environmentally sound management of waste (2006)

25. URL: http://www.webcitation.org/6DpWIgJOW

26. O. N. Paramonova, Engineering Don Gazette, 3 (2013)

27. O. N. Paramonova, E. P. Lisova, Problems of reclamation of waste household, industrial and agricultural production: Materials of IV International scientific ecological conference, part 2 (2015)

28. V. I. Bespalov, O. N. Paramonova, Engineering Don Gazette, 4 (1), (2012)

29. V. I. Bespalov, O. N. Paramonova, Modern scientific achievements in 2013, 92-96 (2013)

30. V. I. Bespalov, O. N. Paramonova, Modern Problems and solutions in science, transport, manufacturing and education in 2012, 76-80 (2012)

31. O. N. Paramonova, Environmental Economics and Conservation, 58-61 (2013)

32. R. G. Adamyan, Building-shaping the built environment, 262-265 (2013)

33. V. V. Privalenko, I. N. Kuznetsov, S. G. Demchenko, Ecological and geochemical monitoring of landfills POMB of Rostov-on-Don (2009)

34. V. I. Bespalov, O. N. Paramonova, European Applied Sciences is an international, 1, 202-204 (2013)

35. A. G. Vetoshkin, Protection of the lithosphere of waste (2005)

36. A. G. Vetoshkin, Theoretical basics of protecting the environment (2002)

37. B. B. Bobovich, Processes and recycling machines (2013)

38. V. I. Bespalov, O. N. Paramonova, Geology problems, planetary, geo-ecology and rational wildlife, 265-267 (2011)

39. V. I. Bespalov, O. N. Paramonova, Ecology and Life, 22-25 (2011) 
40. O. N. Paramonova, Recent scientific questions: Reality and Perspectives, 6, 112-114 (2012)

41. O. N. Paramonova, E. P. Lisova, Innovation processes in the scientific environment, 3, 80-82 (2016)

42. V. Y. Starostin, O. V. Ulanova, Modern problems of science and education, 5 (2013)

43. O. V. Ulanova, V. Yu. .Starostina, Ecology, production, 4, 10-16 (2012)

44. I. M. Sharohovskaya, Waste recycling, 1 (13), 54-61 (2008)

45. V. M. Shmandy, Management of technogenic safety urbosistemy at Obration stage and waste into the environment, 2, 152 (2001)

46. V. M. Shmandy, E. V. Harlamova, T. E. Rigas, Ecological Bulletin of the North Caucasus, 10, 53-63 (2014)

47. V. M. Shmandy, N. A. Klimenko, S. Golik, Environmental Security (2013) 